\title{
Analysis of Sound Insulation Capability and Modulus Elasticity according to Shape and Composition of Natural Fiber Composite Kayu Galam (Melaleuca leucadendra) - Polyester
}

\author{
Ammar Farhan Rayudi ${ }^{1, a)}$, Firman Sidiq ${ }^{1}$, Sulistijono ${ }^{1}$, \\ Abdi Suprayitno ${ }^{1}$ \\ Material and Metallurgical Engineering, Institut Teknologi Kalimantan, Soekarno-Hatta KM. 15 Balikpapan \\ Utara, Balikpapan 76127, \\ Indonesia \\ a) ammar.farhan2204@gmail.com
}

\begin{abstract}
Making and testing of sound insulation materials from natural fiber composite (Galam wood fiber and polyester matrix) to analyze sound transmission loss and modulus of elasticity. Wood material chosen due to the availability of abundant so easyily obtained and also a waste Galam wood is wasted in the process of building construction. Natural fiber shape that used is sawdust and wood chips and using unsaturated polyester as matrix. Speciment made in disc shape with $10 \mathrm{~cm}$ of diameter and $6 \mathrm{~mm}$ thick. Sound intensity measured in insulated room with sound level meter and speaker as sensor and source and run with variation in frequency of transmitted sound wave. With sound transmission loss theory, sound insulating capability could be analyzed. Measurement of modulus of elasticity is needed as a consideration in their application. The result of this research are sound insulation property is less than matrices even the critical frequency was reduced and elasticity was increasing with increasing of the composition of the filler material.
\end{abstract}

Keywords: Composite, Galam Wood, Polyester, Sound Insulation, Elasticity

\section{INTRODUCTION}

A 20-years study in America involving 253 male and female volunteers found that general hearing loss can affect the ability to remember and influence mental health. The study found that airborne noise levels due to passenger plane also affect the risk of high blood pressure. There are also some data from previous studies showing that the risk of heart disease and stroke can increase with the number of plane sound exposure to people living in areas close to the airport. Industrial areas, highways, and developing areas can also be areas with high levels of hearing damage.

In recent years, several studies have developed new materials and technologies to improve the nature of sound absorption and some use composite materials but still in limited quantities (Callister \& Rethwisch, 2010). Composites are artificial materials that have a multiphase which has the desired combination for the best properties of the constituent phase. Composites are classified into particle amplifier, fiber reinforcement, and structural. Composites composed of continuous and discontinuous continuous matrix and reinforced particles, short fibers or wishkers are called particle composites. Natural / Vegetable / Natural Fiber, is a fiber made from vegetable materials such as palm, coconut fiber, banana stem, tree fiber, residue from sawn, and other vegetable materials which can be used as fiber. Its use is also diverse as an anti-shock vest with banana stem fiber, the interior of the train by using fibers from coconut trees, anti-radar materials and so forth. But the role of the use of vegetable fibers is not to provide a reinforcing effect, but only as a mass enhancer of the composite material so as to have low strength and stiffness, even decreasing the strength and rigidity of the 
previous matrix.

Cajuputi or Galam wood is one of the most important plant species in the essential oil industry. This plant can grow on marginal land that is generally close to the community settlement which is usually a society with weak socioeconomic conditions. Eucalyptus plants are one of the most potent plant species in land rehabilitation, ecologically and economically (Han et al., 2015). Galam timber includes timber with class III durability and class II power, used for firewood, small piles, building poles, sources of raw materials for wood processing industries. The foundation of stilts house in South Kalimantan generally use Galam wood with size of $10 \mathrm{~cm}$ diameter and length of 4-7 meters, Galam wood used for construction materials have criteria such as straight shape, the smallest diameter $4-15 \mathrm{~cm}$, length varies 2, 4, or 7 meters.

Galam wood is cheap and easy to obtain, so it can be used in wider application. Currently galam timber is only used for trestle in the construction process of houses and buildings, then become wasted afterwards when the nature of the wood has not changed and is still able to be used for other applications. The polyester being the matrix of this study was chosen because it has weather resistance properties and ease of gain and ease of manufacturing process for the composite material. The main subject of this research is to analyze the effect of adding wood galam in two different forms on polyester matrix into composite material on the nature of sound insulation and its elasticity.

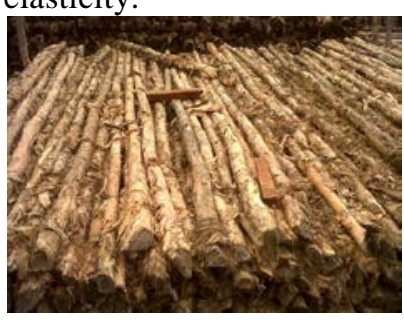

(a)

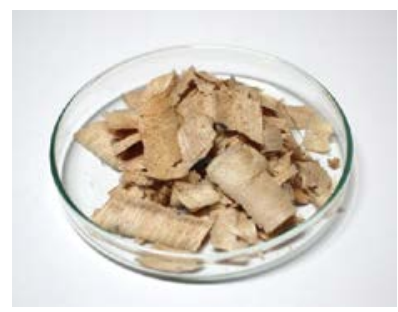

(b)

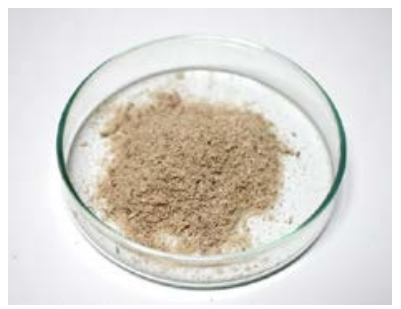

(c)

FIGURE 1. Galam Wood Fiber; (a) Wood Galam; (b) Wood Chip; (c) 


\section{MATERIALS AND METHODS}

\section{Materials}

The materials used in this study were unsaturated polyester resins (Yukalac 157 - BQTN) and commercially obtained catalysts from UD. Mahakam Fiber Glass, Samarinda, East Kalimantan, Indonesia. Galam wood that has been through the process of saws and shavings process. Saw dust and shavings of wood was taken. The particle size of saw dust used was 30 mesh and $10 \mathrm{~mm}$ for the size of the wood chip particles used (figure 1). Galam wood used is obtained from Tanah Grogot, East Kalimantan, Indonesia.

\section{Composite Manufacturing}

Mixing of wood fiber and polyester resins is carried out directly on the mixing glass. Both ingredients are mixed with the composition of $7 \%, 11 \%, 14 \%$ and $18 \%$ filler in the form of process of wood of Galam from 2 forms. For comparison, polyester is also molded without fillers. The catalyst acting as a polyester hardener is mixed before the filler material is mixed with the resin. The mixture of resin and wood is printed on a mold made of pvc and polypropylene with a disc shape with a diameter of $100 \mathrm{~mm}$ and a thickness of $6 \mathrm{~mm}$ for sound insulation samples and beams measuring $300 \mathrm{~mm}$ x $50 \mathrm{~mm}$ x $5 \mathrm{~mm}$ for the elasticity test sample. Material dimension validation is performed to verify the size of the sample to be used and if it does not meet the criteria will be adjusted with the grinding wheel.

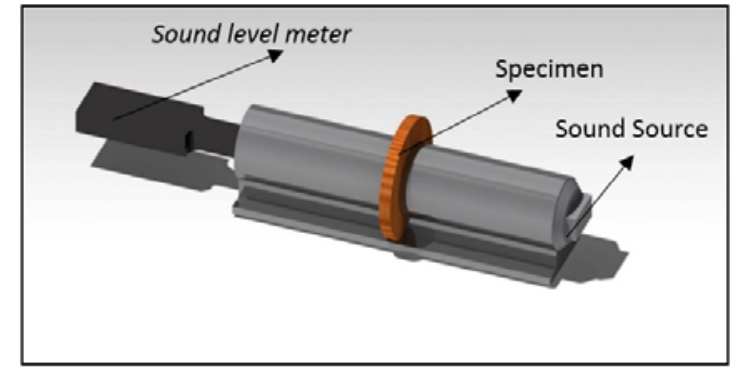

FIGURE 2. Sound Insulation Testing Method

\section{Method and Testing Instrument}

Sound insulation testing uses the principle of transmission loss by measuring the reduced transmission of sound received by the sensor after it penetrates the material adopting the ASTM E90 standard. The test is performed by sounding the sound source at a certain frequency and measuring it with a sound level meter at the other end and comparing the test results with a large sound intensity if the specimen is not mounted as a barrier as shown in Figure 2. The instruments used are Sound Level Meter and Speaker with Tone Generator to produce sound according to the frequency used. The frequency used is as shown in Table 1.

The calculation method used to calculate the value of sound transmission loss in the test is by the formula

$$
\text { STL = Li-Lo }
$$

where:

Lo is sound pressure before passing the specimen $(\mathrm{dB})$

$\mathrm{Li}$ is sound pressure after passing the specimen $(\mathrm{dB})$

Both values above are measured by Sound Level Meter instrument. 
TABLE 1. Research Frequency

\begin{tabular}{c} 
Frequency (Hz) \\
\hline 125 \\
250 \\
500 \\
800 \\
1000 \\
2000 \\
\hline
\end{tabular}

The elasticity modulus test was performed by bending method in which the specimen was given the exact loading in the middle of the specimen and then measured the deflection of the specimen to be calculated to determine its elastic modulus. Micro observation using optical microscope with 63x spin to observe the effect of matrix material on wood surface morphology in order to analyze the effect of matrix on soundproofing and observe the interaction of polyester matrix to wood surface of Galam. Microscopic observations were performed with a Zeiss Primotech microscope.

\section{RESULT AND DISCUSSION}

\section{Material Sound Insulation Properties}

The data of the sound insulation test can be used to analyze the effect of the filler on the composite material in order to determine the efficiency of the filler in the composite material. The effect of the composite material composition can affect the ability of sound insulation. After the insulation testing adopted from the ASTM E90 standard that has been used in the industrial world, the result of the test in Figure 3 shows effect of material behavior on the sound propagating through the material.

Based on fig. 3, the highest insulation value is a sample with a composition of $7 \%$ saw dust with a value of $20.3 \mathrm{~dB}$. The sample has the performance tertigginya at $800 \mathrm{~Hz}$ frequency, but at frequencies of less than or more than $800 \mathrm{~Hz}$, has decreased significantly so that in the application, the material can only be used at a static frequency so it can not be used for applications with dynamic sound source. It is possible that other samples may also have the same STL value as the $7 \%$ sample of saw dust but in this test, these frequencies are not included in the frequency being analyzed.

Comparison of materials can also be done by looking at the average value of sound insulation on the test results, but the average value can only be used for analysis of sound sources with dynamic frequencies. Comparison can be seen in Fig. 3 The figure shows that increasing the filler composition actually decreases the mean value on each composite material containing wood chip, but in the sample with the saw dust filler has the highest mean value in the $14 \%$ sample of saw dust, so in its application, A sample of $14 \%$ saw dust is the most able sample to hold the sound at the sound source with dynamic frequency. From the results of the above analysis which refers to the average STL value of each material, it can be seen that the shape of the material may affect the sound insulation properties although the maximum value remains in the matrix of the material, the polyester and according to the trend of the sound insulation value of the composite material, It is likely that adding a filler can improve the sound absorption properties. 


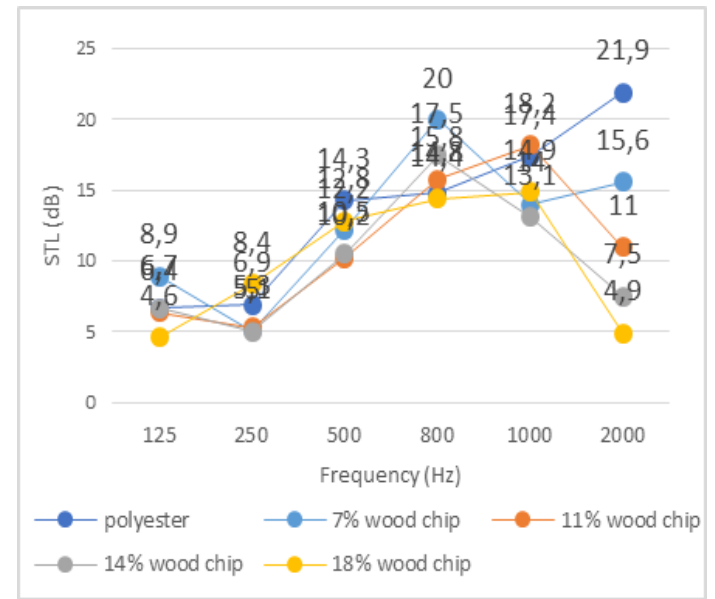

(a)

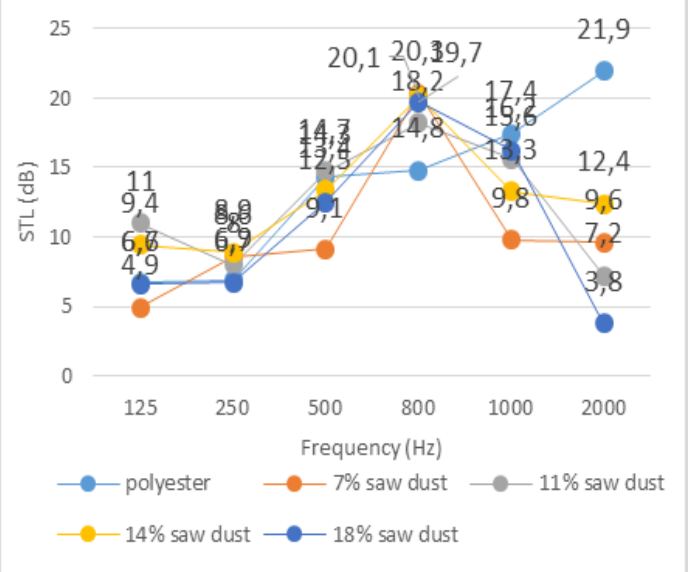

(b)

FIGURE 3 Woodchip Sound Test Result Curve (a); Saw Dust Sound Test Result Curve (b)

Based on figure 3 (b), the highest insulation value is a sample with a composition of $7 \%$ saw dust with a value of $20.3 \mathrm{~dB}$. The sample has its highest performance at a frequency of $800 \mathrm{~Hz}$. The composite material with sawdust filler has an increased tendency at $800 \mathrm{~Hz}$ frequency so that in its application, saw dust can be used at the sound source with that frequency. Another factor that underlies the application of such material is only for static frequencies is that the graph decreases significantly at frequencies less than or more than $800 \mathrm{~Hz}$ so it can not be used for applications with dynamic frequency sound sources. It is possible that other samples can also have the same STL value as the $7 \%$ sample of saw dust but in this test, the frequency is not included in the frequency analyzed.

Based on image data 4, the highest insulation value is a sample with a composition of $7 \%$ wood chip with a value of $20 \mathrm{~dB}$. The sample has its highest performance at a frequency of $800 \mathrm{~Hz}$. Composite materials with shavings have different tendencies compared to composite materials with sawdust fillers, at higher compositions, these materials have higher critical frequencies. The graph shows an insignificant decrease in the insulation capability of sound at higher and lower frequencies compared to the sample with the sawdust filler, so that the application can be used on a sound source with a more dynamic frequency.

\section{ELASTIC PROPERTIES OF MATERIAL}

The composite material has been tested by bending method to determine the value of elasticity and then can be compared with the sound insulation value obtained from the previous test and also can be determined the application of the material in the future. The result of elasticity test is shown in Figure 5. Composite material has increased elasticity value due to the addition of filler, either saw dust and with wood chip, but the value of elasticity increase is different. Significant improvements occur in composite materials with saw dust fillers up to a large elasticity of nearly three times the size of the elasticity of composite materials with wood chip.

Sawdust used as a filler with a large particle size still maintains the flexibility of the matrix so that its elasticity value is low. The loading conditions provide greater deflection in the composite material with the sawdust filler. Composite materials with sawdust filler can increase the elasticity of the matrix so that the material becomes more rigid in loading. Material deflections that occur during loading tend to be less because the material is more able to withstand loads. Applications of materials requiring high stiffness are strongly advised to use polyester composite materials with sawdust fillers.

It shows that the particle size of the fillers also has an influence on the composite material and the particle size also affects the dispersion and distribution capability of the material in order to increase uniformity in the load distribution. The result of elasticity analysis of the above materials does not show a direct correlation to the material sound insulation capability or in other words, the mechanical properties have 
no effect on the sound insulation properties.

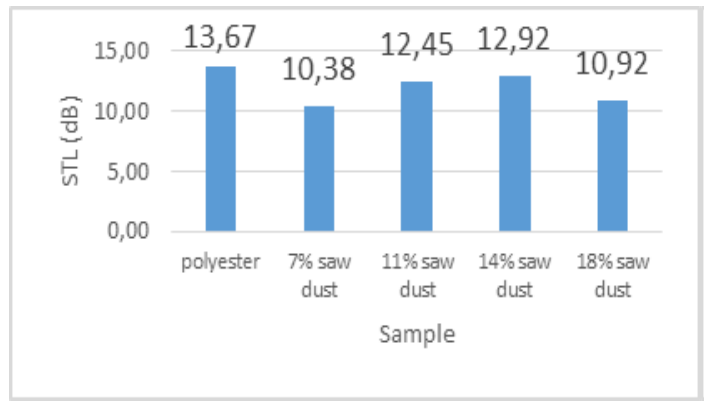

(a)

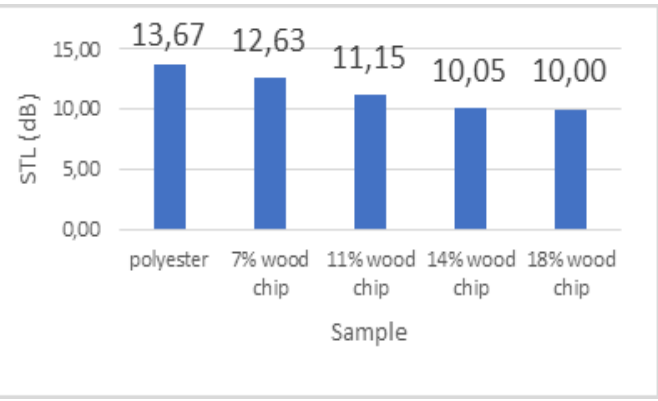

(b)

FIGURE 4 Comparison of mean values of Sound Insulation, (a) Sawdust Fillers, (b) Woodchip fillers

\section{Micro Observation Analysis}

Tahle Micro-observations were performed for microscopic morphological observations of the material. The morphology of the material in focus is the morphology of wood fibers on the condition has not been used as filler and after becoming a composite material. Comparison of the morphological shape of the material can be observed in Figure 6 The results of micro observations show morphological differences, in saw dust and wood chip appear to have a coarse and colorless surface not too shiny because it has not been saturated by polyester resins. The wood material Galam that has been given polyester resin undergoes a more shiny change of color and the surface looks less rough like wood without resin.

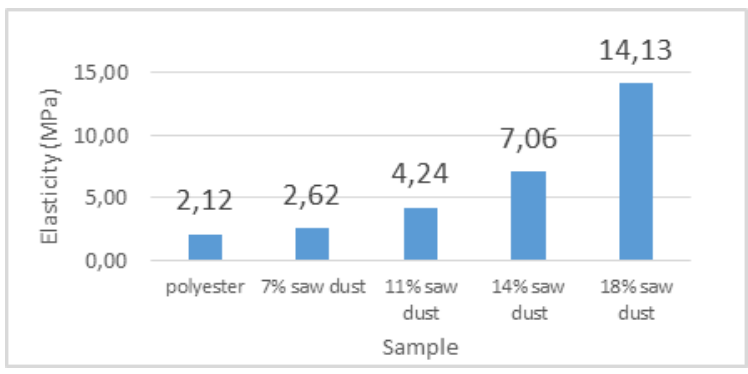

(a)

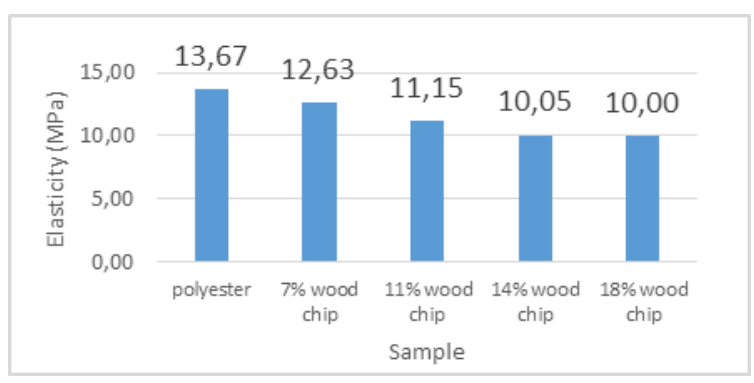

(b)

FIGURE 5. Material Elasticity Value. (a) Saw Dust; (b) Wood Chip

The morphology shows that saturated wood with resin has a stronger sound insulation properties than ordinary wood. The nature of sound insulation relies heavily on wood morphology in which the non-composite wood has a porosity that allows the air to fill up the sound waves. Several previous studies have shown that wood morphology causes the sound insulation properties to increase, but in this case the analysis shows that 
the function of wood decreases the critical frequency of the matrix material so that it can be utilized in applications with lower frequency sound sources. In the analysis of the sound insulation test results (figure 4), the best value of the sample with the least filler, since the resin-loaded cell lumina increases the value of sound insulation, in this case the composition being the most efficient point and near its critical frequency as expressed by (Zhao, Wang, Chang, Yao, \& Cui, 2010).

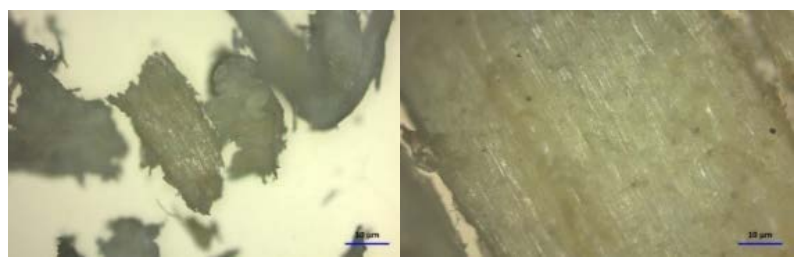

(a)

(b)

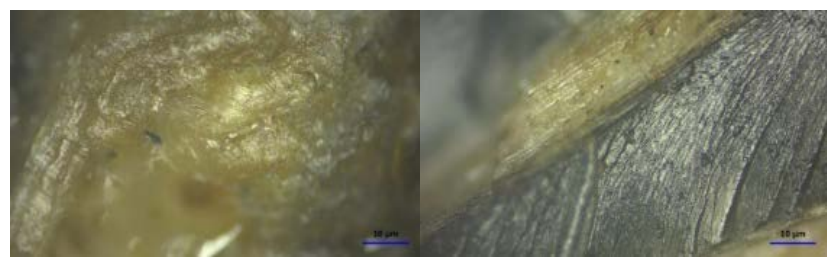

(c)

(d)

FIGURE 6. Micro Observation Results; (A) saw dust; (B) wood chip; (C) resinated wood particle; (D) resinated wood chip

The results of this micro-analysis can also be known damping mechanism that occurs in the composite material, the mechanism that occurs is when the sound waves propagate on the surface of the material, the wave will be reflected and deflected, and there is also a wave weakening phenomenon that dampens large amount of sound energy that leads to the effect Better sound resistance and composite materials with wood chip STL values tend to be lower because the shaft spaces in the wood are not perfectly saturated by the resin causing the air cavity to allow resonance in the material to make the sound propagation easier.

Micro-observations can also show the effect of fillers on the elasticity of composite materials, in the composite material containing the sawdust the more evenly distributed distribution and smaller particle size causes the elasticity value to increase significantly. The capability of polyester resin bond looks more capable of binding to saw dust that has a smaller size than wood chip with larger particle size

\section{CONCLUSION}

The conclusions obtained from the results of this research are:

1. The addition of Galam wood affect to sound insulation properties of polyester material.

2. The addition of Galam wood affects to elasticity of polyester material

\section{REFERENCES}

Callister, W. D., \& Rethwisch, D. G. (2010). Materials Science and Engineering An Introduction Library of Congress Cataloging-in-Publication Data. New York: John Wiley \& Sons.

Han, T., Wang, X., Xiong, Y., Li, J., Guo, S., \& Chen, G. (2015). Light-weight poly(vinyl chloride)-based soundproofing composites with foam/film alternating multilayered structure. Composites Part A: Applied Science and Manufacturing, 78, 27-34. https://doi.org/10.1016/J.COMPOSITESA.2015.07.013

Zhao, J., Wang, X.-M., Chang, J. M., Yao, Y., \& Cui, Q. (2010). Sound insulation property of wood-waste tire rubber composite. Composites Science and Technology, 70(14), 2033-2038. https://doi.org/10.1016/J.COMPSCITECH.2010.03.015 